\title{
Enfrentando o problema dos estágios no desenvolvimento mental das crianças ${ }^{1}$
}

\section{Facing the problem of stages in the mental development of children}

\author{
D. B. Elkonin \\ Tradução: Maria Luísa Bissoto
}

\begin{abstract}
RESUMO $^{3}$
O objetivo central do artigo é discutir o conceito naturalista e evolutivo de desenvolvimento mental, especialmente nos modelos teóricos que defendem uma concepção do desenvolvimento humano pautada numa divisão por estágios, relacionando marcadamente idade cronológica e mudanças intra e interindividuais. Tais modelos teóricos dicotomizam a psicologia da criança nos aspectos necessidade-motivação e intelectuais-cognitivos. Pretendendo superar essa dicotomia, Elkonin propõe que o desenvolvimento humano é melhor entendido como movimento dialético de assimilação, pela criança, desde o seu nascimento, dos objetivos, motivos e normas das relações humanas e de aquisição e interiorização dos modos social e historicamente evoluídos de ação com objetos, presentes em uma coletividade. Essa perspectiva dialética de compreender o desenvolvimento permite: 1. entender o processo de desenvolvimento mental como uma espiral ascendente, antes do que linearmente, 2. explanar a significância funcional dos diferentes períodos do desenvolvimento, clarificando seus padrões de transição, e 3. se mostra relevante como um auxílio para resolver
\end{abstract}

${ }^{1} \mathrm{O}$ artigo foi originalmente publicado em 1971, in Daniil El'konin, Voprosy psikhologii, n. 4, p. 6-20 (1), tradução para o inglês e notas por N. Veresov. A versão inglesa se encontra on line no site Psychology and Marxism Internet Archive $-<w w w . m a r x i s t s . o r g>(2000)$. O artigo foi legalmente traduzido de acordo com as seguintes regulamentações de copyright, referidas no original: 1. sem o objetivo de qualquer vantagem comercial, 2. publicação em uma coleção/periódico aberto ao público e 3. referir o copyright do original.

${ }^{2}$ Professora Doutora, pós-doutorado em Educação, docente no Programa de Pós-Graduação em Educação Sociocomunitária do Centro Universitário Salesiano de São Paulo/Americana, Brasil. E-mail: malubissoto@yahoo.com

${ }^{3}$ Não consta o resumo do artigo em inglês. O resumo acima foi elaborado a partir da leitura do texto. 
a questão da suscetibilidade dos vários estágios do desenvolvimento da criança a tipos particulares de influência.

Palavras-chave: desenvolvimento; atividade social; linguagem; períodos; cultura.

\begin{abstract}
The aim of the article is to discuss the naturalistic and evolutionary concept of mental development, especially in theoretical models which strongly defend a conception of human mental development into stages, relating chronological age and intra and interindividual changes. Such theoretical models dichotomize child psychology in need-motivational and cognitive-intellectual aspects. Intending to surpass this dichotomy, Elkonin considers that human mental development is better understood as a dialectical movement of the assimilation, by the child, since its birth, of the objectives, reasons and norms of human relations and of the acquisition and internalization of the socio-cultural and historically evolved modes of action with objects, within a social group. This dialectical perspective of understanding the development allows: 1. to see the process of mental development as an ascending spiral, rather than linearly, 2. to explain the functional significance of the different periods of development, clarifying their transitional patterns, and 3. to serve as an aid in resolving the question of the susceptibility of the various stages of child development to particular types of influence.
\end{abstract}

Keywords: development; social activity; language; stages; culture.

O problema dos estágios ${ }^{4}$ (2) no desenvolvimento mental da criança é o problema fundamental da psicologia infantil. A elaboração desse problema tem importante significado teórico, pois é por determinar os estágios do desenvolvimento mental e por descobrir os padrões de transição de um estágio para o próximo que a Psicologia eventualmente solucionará o problema das forças

${ }^{4}$ Nota de N. Veresov: O termo russo usado pelo autor é mais bem traduzido como "periodização". O termo "estágio" foi usado na tradução inglesa por ser considerado mais consistente com o uso corrente americano e europeu ocidental. Ao longo do texto manter-se-á o termo estágio, por motivos de consistência linguística, significando, porém, período. 
motivadoras do desenvolvimento mental. Nós argumentamos que toda concepção das forças motivadoras do desenvolvimento mental deve primeiro ser testada no campo de comprovação da teoria dos estágios de desenvolvimento.

A solução correta do problema dos estágios de desenvolvimento determinará, em grande medida, a estratégia empregada na construção de um sistema educacional abrangente para a geração vindoura, em nosso país. O significado prático desse problema aumentará conforme nos aproximarmos do ponto em que deveremos elaborar os princípios de um sistema unificado de educação pública, que abranja todo o período da infância. Devemos enfatizar o fato de que a construção de tal sistema em acordo com as leis dos estágios de desenvolvimento infantil é possível apenas numa sociedade socialista; pois é somente em tal sociedade que há o máximo interesse no desenvolvimento global e harmonioso das habilidades de cada um dos seus membros e, consequentemente, no uso mais pleno possível do potencial de cada estágio do desenvolvimento.

Presentemente, a psicologia infantil soviética é guiada por uma concepção de estágios de desenvolvimento baseada no sistema de criação e educação infantil existente. Os processos de desenvolvimento mental estão intimamente conectados com a educação e criação da criança; ao mesmo tempo, a organização e estrutura de nosso sistema educacional são, em si mesmos, fundados em vasta experiência prática. É natural que a divisão da infância em estágios, para as metas e os objetivos da pedagogia, se aproxime tão estreitamente do padrão real. Entretanto, eles não coincidem. Mais importante, essa decomposição em estágios não pode, de nenhum modo, prover uma solução para a questão das forças motivadoras no desenvolvimento da criança ou para os padrões de transição de um estágio para o próximo. As mudanças que têm lugar ao longo da educação e criação revelam que à "divisão pedagógica dos estágios" falta uma fundamentação teórica firme, sendo incapaz de responder a um número de questões práticas essenciais; por exemplo, quando a educação escolar deveria começar, que características especiais a educação deveria conter no momento de uma transição para um novo estágio, e assim por diante. Assim, o conceito existente de estágios de desenvolvimento está se aproximando de uma crise. Durante a década de 1930, a questão dos estágios de desenvolvimento recebeu grande quantidade de atenção de P. P. Blonsky e de L. S. Vygotsky, que foi quem, aliás, lançou a fundamentação para a psicologia infantil soviética. Infelizmente, nós não temos feito nenhum trabalho fundamental sobre esse problema desde aquela época.

P. Blonsky apontou para o fato que os processos de desenvolvimento mental estão sujeitos à mudança histórica e, especificamente como novos estágios da infância, emergiram ao longo do curso da história. Ele escreveu: 
O homem moderno, sob condições favoráveis ao seu desenvolvimento, se desenvolve mais e mais rapidamente do que os seres humanos de épocas históricas anteriores. Consequentemente a infância não é um fenômeno imutável, eterno: é diferente a cada diferente estágio da evolução no mundo animal, e é diferente também a cada diferente estágio do próprio desenvolvimento histórico da humanidade. Quanto mais favoráveis as condições econômicas e culturais do desenvolvimento, mais rápido é o passo. Em uma sociedade comunista as crianças se desenvolverão mais rápido e naturalmente serão muito mais desenvolvidas que as crianças de hoje, na mesma idade (BLONSKY, 1934, p. 326).

Blonsky continua:

Ao mesmo tempo, vemos que nem a juventude (isto é, a continuação do crescimento depois da puberdade) não é, de forma alguma, uma característica humana universal: no caso das nações ou grupos sociais vivendo sob condições desfavoráveis, o crescimento e o desenvolvimento cessam na puberdade. Assim, a juventude não tem sido um fenômeno eterno; antes, ela se constitui numa aquisição tardia da humanidade - na verdade, uma que surge quase exclusivamente com a época histórica (1934, p. 326).

Blonsky foi um oponente das noções puramente evolutivas quanto ao curso do desenvolvimento infantil. Ele considerou o desenvolvimento da criança sendo primariamente processo de transformações qualitativas, acompanhado por rupturas e saltos repentinos. Ele escreveu que "essas mudanças podem ocorrer na forma de crises agudas, ou podem ter lugar gradualmente, quase imperceptivelmente". Concordemos em chamar esses momentos na vida de uma criança, que são distintos uns dos outros por maiores ou menores crises, de "períodos" ou "estágios", respectivamente. Ainda, designemos aqueles momentos na vida de uma criança que apenas fluem de um para outro como "fases" (3) (BLONSKY, 1930, p. 7).

Nos últimos anos de sua vida, L. S. Vygotsky estava no processo de escrever um importante livro sobre a psicologia infantil. Embora alguns capítulos tenham adquirido uma forma final, outros foram preservados apenas como apontamentos ou notas sobre material de leitura; o próprio Vygotsky preparou para publicação o capítulo intitulado "O problema da idade", que apresenta implicações gerais críveis e uma análise teórica dos materiais então existentes - soviéticos e estrangeiros - sobre o problema dos estágios do desenvolvimento mental da criança. Vygotsky escreveu: 
Podemos provisoriamente definir idade psicológica como uma época, ciclo ou estágio de desenvolvimento específico, como um período do desenvolvimento definido, relativamente autocontido, cuja significância está determinada pelo seu lugar no ciclo geral do desenvolvimento e em cada um dos quais as leis gerais do desenvolvimento são expressas de maneira qualitativamente distinta. Nesse sentido, nós podemos comparar níveis etários no desenvolvimento infantil com as idades históricas, ou eras, no desenvolvimento da humanidade, com as épocas evolucionárias no desenvolvimento da vida orgânica ou com épocas geológicas na história do desenvolvimento da Terra. Na transição de um nível etário para um outro encontramos a emergência de novas estruturas, que estavam ausentes nos períodos anteriores; podemos ver uma reorganização e alteração do inteiro curso do desenvolvimento. Assim, o desenvolvimento da criança é além de uma transição contínua de um nível etário para outro, acompanhado por mudanças no desenvolvimento da personalidade da criança. O estudo do desenvolvimento infantil é o estudo da transição da criança de um estágio a outro e a mudança na sua personalidade em cada período etário conforme essas mudanças ocorrem sob condições sócio-históricas concretas. (s/d, p. 6).

"Nós já sabemos", Vygotsky continua, “onde as fundações reais de uma teoria de períodos etários na infância estão para ser buscadas. Somente mudanças internas no curso do desenvolvimento em si, somente breves rupturas e pontos de virada durante o desenvolvimento, podem nos dar uma fundação confiável para determinar aquelas épocas básicas na formação da personalidade da criança, que chamamos "idades"” (s/d, p. 23).

Vygotsky conclui sua descrição das características básicas dos períodos transacionais no desenvolvimento, como se segue:

Assim, vemos desvelar ante nós um padrão distinto e perfeitamente regular, pleno do mais profundo significado. Períodos de estabilidade são interrompidos por períodos de crises (4). E essas últimas são as rupturas e pontos de virada no desenvolvimento, novamente confirmando a tese de que o desenvolvimento da criança é um processo dialético, um processo no qual a transição de um estágio para o próximo ocorre não através da evolução, mas através da revolução. Mesmo se idades de crise não tivessem sido descobertas empiricamente, uma análise teórica isolada teria necessitado a inclusão desse conceito em qualquer esquema de desenvolvimento. Como está, à teoria é somente deixada a tarefa de validar e interpretar o que já tem sido estabelecido através de investigação empírica. (s/d, p. 34). 
É nossa visão que as abordagens de Blonsky e Vygotsky para o problema de estágios de desenvolvimento devem ser mantidas, mas deveriam ser adicionalmente expandidas à luz do conhecimento presente, concernente ao desenvolvimento mental da criança. Isso deveria envolver o seguinte: primeiro, uma abordagem histórica da média de desenvolvimento e a questão da emergência de períodos distintos da infância no curso do desenvolvimento histórico da humanidade; segundo, uma abordagem de cada estágio etário na perspectiva da posição por ele ocupada no ciclo geral do desenvolvimento mental da criança; terceiro, um conceito de desenvolvimento mental como um processo dialeticamente contraditório, um processo que procede não ao longo de um padrão evolutivo, mas ao longo de um padrão marcado por rupturas na continuidade e a emergência qualitativa de novas estruturas no curso do desenvolvimento; quarto, a discriminação de pontos críticos no desenvolvimento mental como necessários e requisitados pontos de virada ${ }^{5} \mathrm{e}$ o reconhecimento desses pontos críticos como importantes critérios objetivos das transições de um período de desenvolvimento para o seguinte; e quinto, a discriminação de transições qualitativamente diferentes e, em conexão com isso, distinguir entre "períodos", "estágios" e "fases" no desenvolvimento mental.

Blonsky e Vygotsky nunca conseguiram colocar seus princípios de estágios de desenvolvimento para funcionar, devido à ausência de condições para solucionar o problema das forças motivadoras do desenvolvimento mental das crianças. Na década de 1930, a resposta para esse problema revolvia-se em torno dos fatores do desenvolvimento, em torno da questão dos papéis relativos do meio e da hereditariedade no desenvolvimento mental. Embora ambos os investigadores tentassem encontrar um modo de sair do impasse criado pela teoria dos "fatores de desenvolvimento", embora vissem seus limites metodológicos e científico-práticos, e embora Vygotsky lançasse os fundamentos para a elaboração do problema da aprendizagem e do desenvolvimento, nenhuma de suas pesquisas teóricas levou à solução do problema. Isso, por sua vez, impediu qualquer estudo especial do problema dos estágios de desenvolvimento.

Uma das mais importantes realizações da psicologia soviética no final da década de 1930 foi a introdução do conceito de atividade na pesquisa sobre a gênese e desenvolvimento da mente e consciência (por meio das investigações de A. N. Leontiev e S. L. Rubinshteyn). O resultado esteve também nos princípios para distinguir seus estágios individuais. E, pela primeira vez, a solução quanto ao problema das forças motivadoras do desenvolvimento mental das crianças foi considerada como tendo relevância direta para a questão dos princípios para distinguir os estágios específicos no desenvolvimento mental.

\footnotetext{
${ }^{5}$ Ou de "viragem".
} 
Essa nova noção foi mais claramente desenvolvida nos trabalhos de A. N. Leontiev, que escreveu:

\begin{abstract}
Dessa forma, ao estudar o desenvolvimento mental da criança devemos começar do desenvolvimento de sua atividade, conforme essa atividade surge das condições concretas, dadas, da vida da criança [...] Vida ou atividade em geral não é construída mecanicamente a partir de formas particulares de atividade. Em um dado estágio, alguns tipos de atividade serão mais proeminentes e mais significativos para o desenvolvimento futuro da personalidade; outros, menos. Alguns tipos desempenharão um papel condutor no desenvolvimento, outros desempenharão um papel menor. Esse é o porquê deveríamos falar da dependência do desenvolvimento mental não da atividade em geral, mas da forma dominante de atividade (5). De acordo com isso, poderíamos dizer que cada estágio do desenvolvimento mental é caracterizado por uma relação dominante da criança para com seu meio, por uma atividade dominante àquele dado estágio. A indicação de uma transição de um estágio para outro é precisamente uma deriva no tipo dominante de atividade, a relação dominante da criança para com suas circunstâncias (1965, p. 591, 592).
\end{abstract}

As investigações experimentais de A. N. Leontiev, A. V. Zaporozhets e seus colaboradores e o trabalho de A. A. Smirnov, P. I. Zinchenko e dos seguidores de S. L. Rubinshteyn têm demonstrado a dependência do nível funcional dos processos mentais sobre a natureza de seus envolvimentos nessa ou naquela atividade. Em outras palavras, processos mentais (dos processos sensório-motores elementares aos processos intelectuais superiores) são dependentes dos motivos e tarefas da atividade nas quais estão envolvidos; são determinados pelo lugar que ocupam na estrutura da atividade (a ação ou operação). Esses fatos têm desempenhado um importante papel na solução de um número de problemas metodológicos na psicologia.

Infelizmente, contudo, essas novas posições não têm conduzido à elaboração de uma teoria correspondente do desenvolvimento psicológico e dos estágios de desenvolvimento. Em nossa opinião, a falha em desenvolver tal teoria é devido ao fato de que aquelas investigações do conteúdo psicológico da atividade têm negligenciado o aspecto objetivo-contextual da atividade, tratando-a como um aspecto situado fora da psicologia. Atenção tem sido exclusivamente devotada à estrutura da atividade, à correlação de motivos e tarefas, ações e operações pertinentes à atividade. A solução para o problema dos estágios no desenvolvimento mental tem também estado restrita pelo fato de que temos estudado somente dois tipos de atividades diretamente relacionadas 
ao desenvolvimento mental na infância - brincar e aprender. De fato, entretanto, nunca podemos compreender o processo de desenvolvimento mental sem investigar exaustivamente o aspecto objetivo-contextual da atividade, ou seja, sem elucidar a questão: com que particulares aspectos da realidade a criança interage ao desempenhar essa ou aquela atividade?

Até o momento presente, nossos conceitos do desenvolvimento mental da criança têm sofrido principalmente de uma separação radical dos processos de desenvolvimento intelectual daqueles do desenvolvimento da personalidade. Um resultado dessa separação é que o desenvolvimento da personalidade, carente de firme fundamentação, torna-se reduzido ao desenvolvimento da esfera das necessidades afetivas ou da esfera das necessidades motivacionais.

Tão primeiramente como na década de 1930, Vygotsky apontou para a necessidade de ver o desenvolvimento do afeto e do intelecto como uma unidade dinâmica. Mas desde aquela época o desenvolvimento dos poderes cognitivos da criança e o desenvolvimento da esfera das necessidades afetivas têm sido considerados como processos completamente independentes, embora paralelos. Na teoria e prática pedagógica, essa noção é refletida na dicotomia entre educação, por um lado, e criação, do outro.

Talvez o mais claro conceito de um desenvolvimento intelectual divorciado do desenvolvimento da esfera das necessidades afetivas seja aquele contido na teoria de J. Piaget. É Piaget quem tem provido o conceito mais completo de como cada estágio individual no desenvolvimento cognitivo emerge diretamente do estágio precedente (em maior ou menor extensão, tal visão do desenvolvimento intelectual da criança é característica de aproximadamente todas as teorias intelectualistas da cognição). A principal limitação dessa visão repousa em sua inabilidade para explicar as transições de um estágio de desenvolvimento intelectual para o próximo. Por que a criança prossegue do estágio pré-operacional para o estágio operacional concreto e então para o estágio operacional formal (termos de Piaget)? Por que a criança avança do pensamento de tipo complexo para o pensamento preconceitual e, finalmente, para o pensamento conceitual (termos de Vygotsky)? Por que há uma transição de um estágio de atividade prática para o estágio de imagens e então para os estágios verbal-discursivos (para usar terminologia corrente)? Não há respostas claras para essas questões. E na ausência de uma tal resposta o modo mais fácil de evitá-las é aludir ou à 
"maturação" ou a outras forças exteriores ao processo real de desenvolvimento mental.

O desenvolvimento da esfera de necessidades afetivas - um desenvolvimento que, como já apontamos, é frequentemente identificado com o desenvolvimento da personalidade - é visto em uma forma análoga: seus estágios são arranjados linearmente, independente do desenvolvimento cognitivo. Aqui, também, o resultado é que somos deixados sem nenhuma explicação para a transição de um conjunto de necessidades e motivos de atividade para um outro conjunto.

Assim, um dualismo peculiar pode ser lido em relação ao desenvolvimento mental, que é então visto como seguindo duas linhas paralelas básicas: a linha do desenvolvimento da esfera das necessidades motivacionais e a linha do desenvolvimento dos processos intelectuais (cognitivos). É esse dualismo e paralelismo que devemos superar para compreender o desenvolvimento mental da criança como um processo unitário.

Subjacente a esse dualismo e paralelismo está uma abordagem naturalística do desenvolvimento mental da criança, uma abordagem que é característica da maioria das teorias estrangeiras e uma que, infelizmente, ainda não foi inteiramente eliminada da psicologia infantil soviética. Tal abordagem, primeiro de tudo, vê a criança como um indivíduo isolado, para quem a sociedade é meramente "um habitat ambiental" sui generis. Segundo, o desenvolvimento mental é visto simplesmente como o processo de adaptação às condições de vida em sociedade. Terceiro, a sociedade é vista como a união de dois elementos mutuamente disjuntos, um "mundo de coisas" e "um mundo de pessoas", ambos sendo elementos primordiais do que é dado neste "habitat ambiental". Quarto, os mecanismos de adaptação ao "mundo de coisas" e ao "mundo de pessoas", que constituem o conteúdo do desenvolvimento mental, são vistos como fundamentalmente separados.

O desenvolvimento mental, então, é visto como o desenvolvimento de mecanismos adaptativos pertinentes a dois sistemas mutuamente disjuntos: o sistema de "criança-coisas" e o sistema de "criança-outras pessoas". É precisamente essa visão que tem dado origem à noção de duas linhas independentes de desenvolvimento mental. Essas, por sua vez, são a origem de duas teorias: a teoria de Piaget do desenvolvimento cognitivo e do intelecto e a teoria da esfera das necessidades afetivas e seu desenvolvimento, como exposto por Sigmund Freud e os neofreudianos. A despeito das diferenças no conteúdo psicológico concreto, essas concepções estão estreitamente relacionadas em suas interpretações básicas do desenvolvimento mental como o desenvolvimento de mecanismos adaptativos de comportamento. Para Piaget, o intelecto é um mecanismo adaptativo e seu desenvolvimento é o desenvolvimento das formas 
da adaptação da criança ao "mundo das coisas". Para Freud e os neofreudianos, os mecanismos de substituição, censura, deslocamento etc. são mecanismos para a adaptação da criança ao "mundo das pessoas".

Devemos enfatizar o fato de que ao ver a adaptação da criança pertinente ao sistema de "criança-coisas", o segundo desses termos (coisas) aparece principalmente como objetos físicos com suas propriedades espaciais e físicas. Ao ver a adaptação da criança em relação ao sistema de "criança-outras pessoas", o último termo aparece como individualidades randômicas com seus traços individuais característicos, temperamentos etc. Se coisas são vistas como objetos físicos e pessoas como individualidades randômicas, então a adaptação da criança a esses "dois mundos" na verdade parece prosseguir ao longo de duas linhas paralelas, fundamentalmente independentes (6).

Superar essa abordagem não é um problema fácil, primariamente porque, para a criança, a realidade que a cerca aparece em duas formas. Encontramos essa divisão da realidade da criança em um "mundo de coisas" e um "mundo de pessoas" em nossas investigações experimentais da natureza do "jogo de papéis" (do desempenhar de papéis sociais) nas crianças em idade pré-escolar. $\mathrm{Na}$ tentativa de elucidar a questão da sensibilidade do jogo de papéis para essas duas esferas da realidade, nós, em alguns casos, familiarizamos as crianças com coisas, suas propriedades e propósitos. Por exemplo, durante uma viagem ao zoológico, poderemos familiarizar as crianças com os animais, seus habitats, sua aparência externa e assim por diante. Embora animais de brinquedo fossem colocados na escola das crianças após a viagem, o jogo de papéis não se desenvolveu. Em outros casos, poderíamos usar uma tal viagem para familiarizar as crianças com as pessoas que serviam à equipe do zoológico, com o padrão de inter-relações de suas funções - o vendedor de ingressos e o coletor de ingressos, os guias, com os atendentes que alimentavam os animais, com o "doutor de animais selvagens" e assim por diante. Depois de tal viagem houve, como regra, extenso e interessante jogo de papéis, em que as crianças "modelaram" as tarefas das atividades dos adultos e as relações entre adultos.

Além disso, nesses jogos, ao conhecimento previamente adquirido pelas crianças sobre animais selvagens foi dado significado e um contexto. Os resultados dessa investigação atestaram o fato de que o jogo de papéis é primariamente sensível ao "mundo das pessoas" - é em seu brincar que as crianças "modelam" os propósitos e motivos da atividade humana e as normas das relações humanas. Ainda, a investigação mostrou que para a criança o mundo ao redor realmente aparece dividido em duas esferas e que há uma forte ligação entre as atividades da criança em ambas as esferas (embora nessa investigação não fôssemos capazes de lançar luz sobre características específicas dessa ligação). 
Superar o conceito naturalista de desenvolvimento mental clama por uma abordagem radicalmente nova das inter-relações entre criança e sociedade. Fomos levados a essa conclusão por uma investigação especial da emergência histórica do jogo de papéis. Em contraste à visão que esse é um fenômeno extra-histórico eterno, hipotetizamos que o mesmo emergiu em um estágio específico do desenvolvimento social, conforme a posição da criança na sociedade mudou no curso da história. O jogo de papéis (role-playing) é uma atividade que é social em sua origem e, consequentemente, social no conteúdo.

Essa hipótese concernente à origem histórica do brincar é sustentada por uma riqueza de material antropológico e etnológico. Esse material demonstra que o jogo de papéis emerge conforme o status da criança na sociedade se modifica. A posição da criança na sociedade tem se modificado no curso da história, mas em todas as épocas e lugares as crianças têm sido parte da sociedade. Nos estágios primevos do desenvolvimento da humanidade, a ligação entre a criança e a sociedade era direta e imediata - a partir de seus primeiríssimos anos, crianças viviam uma vida em comum com adultos. $\mathrm{O}$ desenvolvimento da criança com essa vida comum foi um processo integral e unificado. A criança constituía uma parte orgânica das forças produtivas combinadas da sociedade e sua participação nela foi limitada apenas por suas capacidades físicas.

Conforme os meios de produção e as relações sociais se complexificaram, a ligação entre a criança e a sociedade mudou: essa ligação, previamente direta, agora se tornou mediada pela educação e normas de criação. O sistema "criança-sociedade", entretanto, não mudou, não se tornou um sistema "criança e sociedade" (a conjunção "e" pode, evidentemente, implicar contraste, bem como combinação). Poderia ser mais correto falar de um sistema da "criança na sociedade". No processo de desenvolvimento social, as funções de educação e criação vieram crescentemente a ser assumidas pela família, que se tornou, em si mesma, uma unidade econômica independente. Ao mesmo tempo, as amarras entre a família e a sociedade se tornaram mais e mais indiretas. O conjunto de relações caracterizando a "criança na sociedade" se tornou, congruentemente, obscurecido e cancelado pelo sistema de relações "criança-família" e, com isso, pelas relações entre "a criança-o indivíduo adulto".

Se olharmos para a formação da personalidade no sistema "criança em sociedade", podemos ver como as ligações nos sistemas "criança-coisa" e "criança-indivíduo adulto" assumem um caráter radicalmente diferente. Elas mudam de dois sistemas independentes para um sistema unificado. E, como resultado, o 
conteúdo de cada sistema é essencialmente modificado. Quando examinamos o sistema "criança-coisa" agora vemos que coisas, possuindo propriedades físicas e espaciais definidas, aparecem à criança como objetos sociais: são modos de ação socialmente desenvolvidos com esses objetos, que predominam.

O sistema "criança-coisa" é na realidade o sistema "criança-objeto social". Modos de ação socialmente desenvolvidos com esses objetos não são dados imediatamente como propriedades físicas dos objetos. Não encontramos inscritos nos objetos onde e como se originaram, como podemos operar com eles, como podemos reproduzi-los. Portanto, esse objeto não pode ser dominado através de adaptação, através de uma mera "acomodação" às suas propriedades físicas. Isso deve tomar lugar internamente; a criança deve seguir por um processo especial de aprender os modos sociais de ação com os objetos. Nesse processo, as propriedades físicas de um objeto servem meramente como referentes para a orientação da criança em suas ações com aquele objeto.

Conforme a criança aprende os modos de ação socialmente desenvolvidos com objetos, ela está sendo formada como um membro da sociedade (7) por um processo que inclui suas forças sociais, cognitivas e intelectuais. Para a criança em si mesma (bem como para adultos diretamente envolvidos no processo organizado de educação e criação), esse desenvolvimento aparece, primariamente, conforme a expansão de sua esfera de assimilação da atividade com objetos se expande exteriormente, para incluir mais ações e, superiormente, para um maior nível de proficiência. É em termos desses critérios que a criança compara seu próprio nível e suas próprias capacidades com aquelas dos adultos e outras crianças. Em tal comparação, o adulto aparece à criança não apenas como o balizador de modos sociais de ação com objetos, mas também como uma pessoa performando tarefas sociais específicas.

As características distintivas da descoberta da criança do sentido humano das ações objetais [isso é, ações dirigidas na direção de, ou envolvendo a manipulação de objetos $\left.{ }^{6}\right]$ têm sido mostradas em diversas investigações. Por exemplo, Fradkina (1946) descreveu como, em certo estágio na aquisição de ações objetais, a criança pequena começa a comparar suas próprias ações com aquelas dos adultos. Isso é demonstrado pela criança chamando a si mesma simultaneamente por dois nomes, seu próprio nome e o nome de um adulto. Por exemplo, imitando a ação de um adulto lendo um jornal ou escrevendo, um garoto pode dizer "Misha-Papai", ou uma garotinha, vestindo sua boneca para dormir, pode referir-se a "Vera-Mamãe". L. S. Slavina (1948) mostrou, em suas investigações, como a criança, uma vez que ela tenha descoberto o sentido

\footnotetext{
${ }^{6}$ Nota do editor.
} 
humano das ações objetais, se fixa tenazmente a ele, importando aquele sentido mesmo para as manipulações mais simples.

Essas investigações foram conduzidas sobre material limitado concernente ao desenvolvimento das ações objetais em crianças muito jovens. Mas sugerem que a aquisição pela criança dos modos de ação com objetos a conduzem obrigatoriamente à compreensão do adulto como um portador dos escopos sociais da atividade. Deve ser deixado para investigações adicionais determinar o mecanismo psicológico de transição em cada caso concreto e em cada estágio concreto de desenvolvimento.

O sistema "criança-adulto", por sua vez, também assume um conteúdo substancialmente diferente. $\mathrm{O}$ adulto não mais aparece primariamente como uma coleção de atributos randômicos e individuais, mas como o balizador de certos tipos de atividade, que é social por sua natureza, como o realizador de certas tarefas, como alguém que existe em várias relações com outras pessoas e como uma pessoa que em si mesma se conforma a certas normas. Porém, os escopos e motivos da atividade de um adulto não são externamente visíveis a partir da atividade em si. Externamente, a criança vê essa atividade como a transformação dos objetos e sua produção. As intenções são reveladas somente conforme aquela atividade é conduzida à sua forma acabada, real, na totalidade das relações sociais; mas a criança não é capaz de ver a atividade nesse contexto. Assim se origina a necessidade de um processo especial de aprender os objetivos e motivos da atividade humana e as normas das relações humanas às quais as pessoas se conformam enquanto agem.

Infelizmente, as características psicológicas particulares desse processo (aprender) não têm sido suficientemente investigadas. Entretanto, com base no que conhecemos, podemos oferecer as seguintes hipóteses: a criança aprende os objetivos, motivos e normas das relações na atividade adulta por reproduzir ou imitar relações em sua própria atividade, com as associações e coletividades às quais ela pertence. É notável que no processo de assimilação a criança se confronta com a necessidade de aquisição de novas ações objetais, que são requeridas para performar atividade adulta. Dessa forma, a criança vê o adulto como o portador de novos e mesmo mais complexos modos de ação com objetos, de padrões e normas socialmente elaborados, que são necessários para a orientação no mundo ao redor.

Congruentemente, a atividade da criança com os sistemas "criança-objeto social" e "criança-adulto social" representa um processo unitário, no qual sua personalidade é formada. No curso do desenvolvimento histórico, contudo, esse processo essencialmente unitário da vida da criança em sociedade se bifurca, se separa em dois aspectos. Essa bifurcação cria as precondições para o desenvolvimento hipertrofiado de um dos dois lados. A escola, numa sociedade de 
classes, explora essa possibilidade ao educar algumas crianças primariamente como performadores dos aspectos operacionais e atividades laborativas, enquanto educa outras preferencialmente como os balizadores dos objetivos e motivos daquela atividade. Somente uma sociedade classe-estruturada é caracterizada por tais explorações da bifurcação historicamente estabelecida no processo unitário da vida e desenvolvimento da criança em sociedade.

\section{IV}

As ideias teóricas que elaboramos acima estão diretamente relacionadas ao problema dos estágios no desenvolvimento mental da criança. Voltemos ao material factual acumulado na psicologia da criança. De uma multitude de investigações conduzidas nos últimos 20-30 anos, devemos selecionar aquelas que têm enriquecido nosso conhecimento dos tipos básicos da atividade das crianças. Examinemos brevemente as mais importantes dessas.

1. Até muito recentemente houve um grande volume de incerteza concernente às características contextuais-objetivas da atividade do bebê. Em particular, nós não tínhamos clareza quanto a qual atividade era dominante durante essa idade. Alguns investigadores (L. Bozhovich e outros) consideravam a necessidade do bebê por estímulos externos como primária. Consequentemente, o aspecto mais importante da atividade da criança era o desenvolvimento das ações orientadoras. Outros (Piaget e outros) deram maior atenção ao desenvolvimento da atividade sensório-motora e manipulativa. Um terceiro grupo (G. L. Rozengard-Pupko e outros) enfatizou a significância do fazer contato dos bebês com adultos.

Em anos recentes, pesquisa conduzida por M. I. Lisina e seus associados convincentemente demonstrou que os bebês têm uma forma especial de atividade comunicativa, atividade que é de natureza diretamente emocional. A animação que aparece durante o terceiro mês de vida do bebê e que formalmente foi considerada uma simples reação ao adulto (o estímulo mais forte e mais complexo) é, na realidade, uma atividade complexa com o objetivo de fazer contato com o adulto e empregando seus próprios meios especiais. É importante notar o fato de que essa ação aparece muito antes de a criança começar a manipular objetos ou antes que o ato de preensão tenha sido formado. Depois que a atividade de preensão e manipulação executada junto com adultos foi adquirida, atos de comunicação não são absorvidos no espectro estrutural de uma atividade conjunta; eles não emergem no curso das interações práticas com adultos, mas retêm seus 
próprios significados e conteúdos específicos. Essas e outras investigações têm mostrado que um déficit no contato emocional (e, em toda probabilidade, um excesso de tal contato) exerce uma influência decisiva no desenvolvimento mental nesse período.

Dessa forma, podemos assumir que o contato emocional direto com o adulto representa a atividade dominante do bebê; é em contraste o pano de fundo dessa atividade e, a partir dela, que as ações manipulativas, de orientação e sensório-motoras tomam forma.

2. Essas mesmas investigações estabeleceram o tempo de transição da criança - no final da infância - para a atividade propriamente objetal, isto é, para a aquisição de modos de ação socialmente evoluídos com objetos. Uma aquisição dessas ações é, evidentemente, impossível sem a participação de adultos que as demonstrem à criança e executem-nas com ela. $\mathrm{O}$ adulto é apenas um elemento - embora um elemento chefe - na situação da atividade objetal. O contato emocional direto com o adulto diminui para um papel subordinado; o papel dominante é agora assumido pela cooperação estritamente prática na atividade presente. A criança está absorvida pelo objeto e nas suas manipulações com esse. Vários pesquisadores têm repetidamente chamado a atenção para como a criança parece, assim, estar limitada no campo de suas ações diretas. É nesse ponto que observamos a emergência do "fetichismo objetal": a criança parece não notar o adulto, que está "escondido" pelo objeto e suas propriedades.

Muitos investigadores, soviéticos e estrangeiros, têm mostrado que um intensivo processo de aquisição de operações objeto-instrumentais tem lugar durante esse período, quando a assim chamada "inteligência prática" é formada. Ainda, investigações detalhadas da gênese da inteligência na criança, conduzidas por Piaget e seus associados, têm indicado que é precisamente durante esse período que o desenvolvimento sensório-motor tem lugar, um desenvolvimento que prepara para a emergência das funções simbólicas.

Nós já nos referimos aos estudos de F. I. Fradkina, os quais mostram como, no processo de aprendizagem em ação, esta parece se tornar descolada do objeto sobre o qual ela foi originalmente aprendida: a ação é transferida para outros objetos que, embora similares, não são idênticos ao objeto original. Sobre essa base, as ações são generalizadas. F. I. Fradkina mostrou que é precisamente através do descolamento de ações a partir dos objetos e suas generalizações que se torna possível para a criança comparar suas ações com aquelas do adulto; desse modo, a criança começa a ganhar acesso ao significado e metas das ações humanas.

Esses achados indicam que a atividade dominante na primeira infância é precisamente atividade objeto-instrumental, no curso da qual a criança adquire modos socialmente estabelecidos de ação com objetos. 
À primeira vista, isso parece ser contradito pelo fato de que é durante esse período que a criança desenvolve formas verbais de comunicação com adultos. De um ser sem fala, cujo contato com adultos é por meio de emoções e mímicas, a criança se torna um ser falante, que emprega uma gramática e um vocabulário relativamente amplo. Contudo, análises da comunicação verbal da criança revelam que ela usa a fala primariamente como um meio de cooperação adicional com adultos, no contexto de suas atividades estabelecidas com objetos. Em outras palavras, ela serve como meio de contato puramente prático entre criança e adulto. E, ademais, temos razão para acreditar que as ações objetais em si, e a forma bem sucedida com a qual nós as executamos, são para a criança um modo de promover mais cooperação com adultos. Essas relações comunicativas são em si mesmas mediadas pelas ações objetais da criança. Portanto, o desenvolvimento intensivo da fala - se a fala é vista como um meio de uma cooperação auxiliar com adultos - não contradiz nossa argumentação de que a atividade dominante nesse período é a atividade objetal, na qual a criança aprende modos socialmente desenvolvidos de ação com objetos.

3. Os trabalhos de Vygotsky, Leontiev e outros estabeleceram firmemente para a psicologia soviética o fato de que a atividade pré-escolar dominante é o brincar, em sua forma mais expandida (jogo de papéis). O significado do brincar no desenvolvimento mental da criança nessa idade tem muitos aspectos. Seu significado primário repousa no fato de que no brincar a criança está modelando relações humanas devido a artifícios especiais do brincar; por exemplo, ela assume o papel do adulto, as funções e trabalho do adulto na sociedade, reproduz ações objetais generalizando-as em pensamento representacional; transfere significado de um objeto para outro etc.

Uma ação objetal, tomada isoladamente, não tem "inscritas nela" as respostas a questões como: para que isso foi feito? Qual é seu significado social? Qual é seu motivo real? É somente quando uma ação objetal se torna incorporada em um sistema de relações humanas que podemos descobrir seu verdadeiro significado social, suas proposições enquanto relacionadas a outras pessoas. Esse tipo de "incorporação" também tem lugar no brincar. O jogo de papéis é uma atividade na qual a criança se torna orientada para significados mais universais, mais fundamentais, da atividade humana. Sobre essa base, a criança começa a despertar para atividades socialmente valiosas e significativas, que é o indicador chave da sua prontidão para a escola. Este é o significado central do brincar para o desenvolvimento mental, é sua função dominante.

4. No começo da década de 1930, Vygotsky postulou que a instrução escolar é o elemento dominante no desenvolvimento mental das crianças em idade 
escolar. Naturalmente, nem todo tipo de instrução exerce tal influência no desenvolvimento: é somente a "boa instrução" que tem esse efeito. Cada vez mais a qualidade da instrução está começando a ser julgada exatamente pelo modo como ela influencia o desenvolvimento intelectual da criança. Psicólogos têm conduzido um grande número de experimentos elaborados para determinar como a instrução escolar influencia o desenvolvimento mental. Os limites do presente artigo não nos permitem examinar todas as diferentes perspectivas. Apenas chamamos a atenção para o fato de que a maioria dos investigadores conquanto concebe dos mecanismos internos dessa influência e qualquer que seja o significado que atribua aos vários aspectos da instrução (conteúdo, método, organização) - concorda que a instrução é o fator dominante no desenvolvimento intelectual da criança no princípio da idade escolar.

A atividade de aprendizagem formal (8), ou seja, a atividade através da qual a criança adquire novo conhecimento e para a qual um sistema de instrução deve prover direcionamento apropriado, é a atividade dominante nesse período. As forças intelectuais e cognitivas da criança são ativamente moldadas durante o curso desse processo. A primazia do aprendizado está também refletida no fato de que é essa atividade que media a totalidade do sistema de relações da criança com o entorno dos adultos (aprofundando-se para a comunicação pessoal com a família).

5. Distinguir a atividade dominante durante a adolescência apresenta maiores dificuldades. Essas dificuldades estão associadas com o fato de que, para o adolescente, a atividade primária são ainda os estudos escolares. Para os adultos, o sucesso ou o fracasso na escola continua a servir como o principal critério para avaliar os adolescentes. Ainda, sob a condição educacional presente a transição para a adolescência não é acompanhada por qualquer outra mudança exterior adicional. Porém, é precisamente a transição para o período da adolescência que a psicologia tem distinguido como o mais crítico.

$\mathrm{Na}$ ausência de quaisquer mudanças nas condições gerais da vida e da atividade, é natural que os psicólogos tenham buscado a causa da transição para a adolescência nas mudanças do organismo em si, no processo de maturação sexual, que ocorre nesse período. O desenvolvimento sexual, naturalmente, exerce uma influência no desenvolvimento da personalidade durante esse período, mas ele não é a influência primária. Como outras mudanças conectadas com o crescimento físico e intelectual da criança, a puberdade exerce sua influência indiretamente, através da relação da criança com o mundo ao redor e através da autocomparação com adultos e outros adolescentes, ou seja, somente na totalidade complexa de mudanças que ocorrem nesse período. 
Alguns investigadores têm mostrado como, no começo desse período, uma nova esfera de vida emerge. H. Wallon expressou essa ideia mais claramente quando escreveu:

Quando a amizade e a rivalidade não mais são baseadas na comunidade ou no antagonismo ou tarefas que são feitas ou permanecem para ser completadas; quando amizade e rivalidade parecem expressar uma afinidade ou diferença espiritual; quando parece que têm aspectos pessoais e não estão ligados a cooperação prática ou conflito - isso indica a chegada da maturidade sexual. (1967, p. 194).

Nos últimos anos, investigações conduzidas por D. B. Elkonin e T. V. Dragunova revelaram que uma atividade especial emerge e se desenvolve na adolescência, uma atividade que consiste no estabelecimento de relações pessoais íntimas entre adolescentes. Essa atividade foi nomeada de atividade de comunicação social. Ela difere de outras inter-relações que ocorrem na cooperação prática entre pares pelo fato de que seu principal conteúdo concerne a um outro adolescente como um ser humano com qualidades pessoais definidas. Em todas as formas de atividade identificadas na adolescência, podemos observar como relações são subordinadas ao "código da amizade". Relações interpessoais podem ser, e são, construídas sobre a base não somente do respeito mútuo, mas também da completa confiança e do compartilhamento mútuo de um mundo privado, interior. Essa esfera da vida compartilhada entre amigos é particularmente importante na adolescência. A formação da personalidade adolescente é grandemente influenciada pela formação de relações com os pares do grupo, sobre as bases do código de amizade. O código de amizade reproduz, em seu conteúdo objetivo, as normas mais universais de inter-relações que vigoram para os adultos na sociedade.

A comunicação social, então, é a forma específica na qual as relações adultas são reproduzidas na adolescência e o meio pelo qual a adolescência se torna mais completamente versada nas normas que guiam a sociedade adulta. Assim, é razoável assumir que a atividade dominante durante esse período de comunicação social, a atividade de construir relações com amigos, sobre as bases de normas éticas e morais, media as ações da adolescência.

Podemos, entretanto, ir além. A comunicação pessoal, construída em completa confiança em um mundo privado compartilhado em comum, é a atividade na qual a maioria das perspectivas universais de vida da criança são formadas, suas perspectivas sobre as relações humanas, sobre seu próprio futuro, em suma, 
os sentidos pessoais da vida. Dessa forma, começamos a formação da consciência autorreflexiva, sua autoconsciência forma-se como uma "consciência social reorientada para o interior" (VYGOTSKY, s.d.). Isso, por sua vez, permite a emergência de novos motivos e objetivos, que direcionam a própria atividade da criança em direção ao futuro e ao longo dos canais da educação e carreira.

Fomos capazes apenas de expor brevemente os fatos mais importantes concernentes às características objetivo-contextuais dos tipos dominantes de atividade que foram já distinguidas, sobre as bases das quais podemos separar todos os tipos em dois grandes grupos.

O primeiro grupo inclui atividades que são acompanhadas por uma orientação intensiva nos sentidos fundamentais da atividade humana e pela aquisição dos objetivos, motivos, e normas de relações humanas, isto é, atividades pertinentes ao sistema de "criança-adulto social". Há, naturalmente, diferenças essenciais entre o contato emocional direto do bebê, do brincar do jogo de papéis na criança pequena e o contato pessoal íntimo entre adolescentes - diferenças tanto em termos de conteúdos concretos como em termos da profundidade da imersão da criança na esfera de motivos e objetivos da atividade adulta. São, de fato, essas diferenças que nos permitem formar uma imagem da progressão de diferentes estágios como um tipo especial de escada para a progressiva assimilação pela criança da esfera de motivos e objetivos na atividade. Apesar disso, essas atividades têm um conteúdo básico comum: é precisamente nesse grupo de atividades que o desenvolvimento primário da esfera de motivos-necessidades tem lugar.

O segundo grupo consiste de atividades com as quais a criança adquire ambos, modos de ação com objetos socialmente desenvolvidos e os padrões que distinguem os vários aspectos desses objetos, ou seja, essas são atividades no sistema "criança-objeto social". Naturalmente, existem diferenças essenciais entre os tipos de atividade desse grupo. A manipulação de objetos da criança muito jovem guarda pouca semelhança para com a atividade de aprendizagem da criança pequena em idade escolar e mesmo menos semelhança para a atividade vocacional e orientada para a carreira do adolescente mais velho. Na verdade, o que o domínio de operações objetivas envolvendo uma colher ou copo tem em comum com dominar a matemática ou a gramática? E ainda assim eles têm uma característica comum: são todos elementos da cultura humana. Têm uma origem comum e um lugar comum na vida da sociedade; todos representam o resultado de um produto da história. Através da aquisição dos modos de ação socialmente envolvidos com objetos, a criança se torna mais plenamente orientada no mundo objetivo, seus poderes intelectuais são moldados, ela se torna uma parte das forças produtivas da sociedade. 
Aqui devemos enfatizar um ponto: quando falamos da atividade dominante e seu significado para o desenvolvimento da criança nesse ou naquele período, isso de nenhuma forma significou implicar que a criança não poderia, também, simultaneamente, desenvolver-se em outras direções. Em cada período, a vida da criança tem muitos aspectos e as atividades das quais sua vida é composta são variadas. Novos tipos de atividades aparecem, a criança forma novas relações com seu entorno. Quando uma nova atividade se torna dominante, ela não cancela todas as atividades previamente existentes: ela meramente altera seu status com o amplo sistema de relações entre a criança e seu meio, o qual, portanto, se torna crescentemente mais rico.

Se tomarmos os tipos de atividade da criança que anteriormente distinguimos e arranjá-los em grupos, de acordo com a ordem em que elas se tornam a atividade dominante, obtemos a seguinte série:

Contato emocional direto $1^{\circ}$ grupo

Manipulação de objetos $2^{\circ}$ grupo

Jogo de papéis $1^{\circ}$ grupo

Atividade de aprendizagem $2^{\circ}$ grupo

Contato pessoal íntimo $1^{\circ}$ grupo

Atividade vocacional ou orientada para uma carreira $2^{\circ}$ grupo

Assim, o desenvolvimento da criança é composto, de um lado, por períodos caracterizados principalmente pela assimilação dos objetivos, motivos e normas das relações humanas e, nessa base, pelo desenvolvimento da esfera necessidade-motivação e, de outro lado, de períodos caracterizados principalmente pela aquisição de modos socialmente evoluídos de ação com objetos, e, nessa base, a formação das forças intelectuais e cognitivas da criança, suas capacidades operacionais e técnicas.

A partir do que observamos acima podemos formular uma hipótese sobre a alternância de períodos de desenvolvimento: períodos em que vemos um desenvolvimento predominante da esfera motivacional da criança alternar regularmente com períodos nos quais observamos o desenvolvimento predominante das capacidades operacionais e técnicas.

Um considerável corpo de conhecimentos na psicologia soviética e na estrangeira nos permite discriminar duas transições agudas no desenvolvimento mental da criança. Primeiro, a transição da infância mais precoce para a idade pré-escolar, usualmente chamada de crise dos três anos, e, segundo, a transição da idade escolar para a adolescência, comumente referida como a crise da puberdade. Uma comparação dos sintomas dessas duas transições revela uma grande similaridade entre elas. Em ambos os períodos, a criança manifesta uma 
tendência em direção à independência, bem como uma série de fenômenos negativos conectados às suas relações com os adultos. Inserindo esses pontos de virada no esquema de períodos de desenvolvimento na infância, chegamos ao padrão geral de períodos, estágios e fases mostrados na figura aposta.

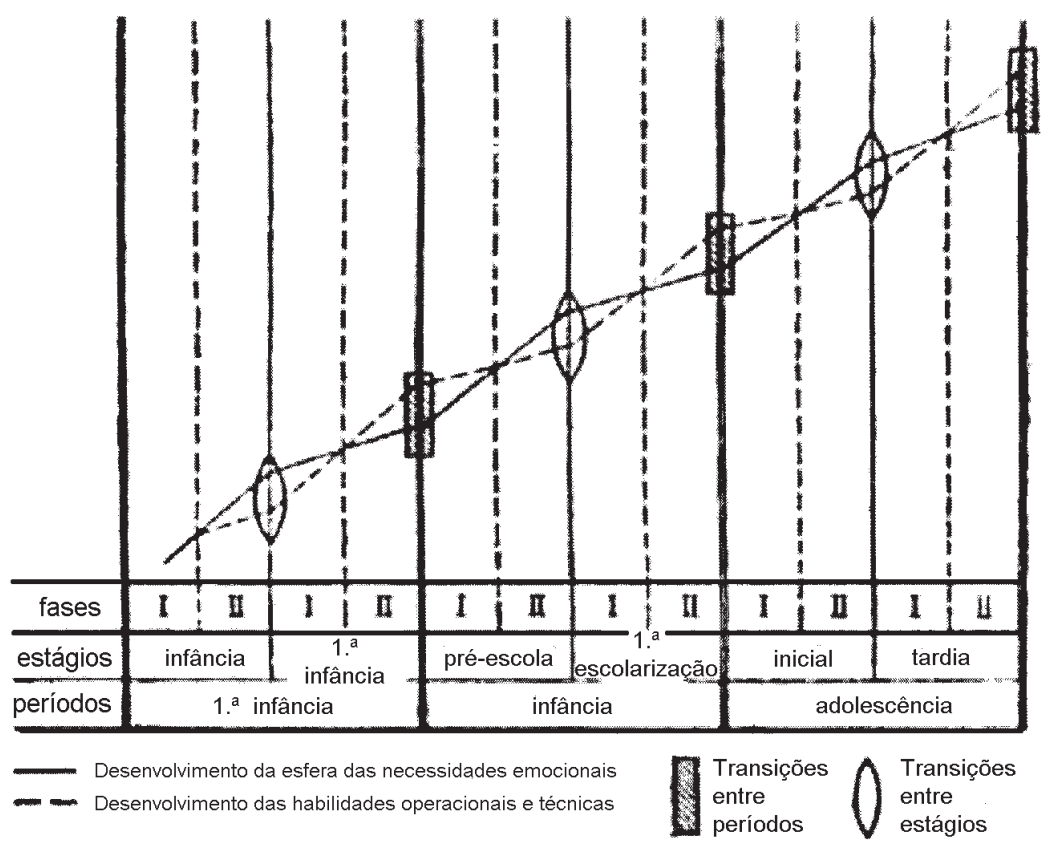

Como a figura mostra, cada época consiste de dois períodos regularmente conectados. O primeiro desses é o período dominado pela aprendizagem dos objetivos, motivos e normas da atividade humana e pelo desenvolvimento da esfera necessidade-motivação. Nesse ponto, ocorre uma preparação para a transição para o segundo período, dominado pela aquisição de modos de ação com objetos e o desenvolvimento de habilidades técnicas e operacionais.

Todas as três épocas (primeira infância, infância e adolescência) estão estruturadas sob os mesmos princípios e são compostas de dois períodos regularmente conectados. A transição de uma época para a próxima é marcada por uma discrepância entre as capacidades operacional e técnica da criança e as tarefas e motivos que constituem a estrutura das quais essas capacidades são geradas. 
Pouco conhecemos sobre a transição de uma fase em um período para a próxima.

Qual, exatamente, é a significância teórica e prática de nossas hipóteses concernentes aos estágios de desenvolvimento e ao esquema periódico que temos construído com base nessas hipóteses? Antes de tudo, o significado teórico principal de nossas hipóteses repousa no fato de que ela nos permite sobrepassar a dicotomia na psicologia da criança entre o desenvolvimento dos aspectos necessidade-motivação e os aspectos intelectuais e cognitivos da personalidade; ela nos permite mostrar sua unidade dialética em oposição. Segundo, nossa hipótese nos capacita a ver o processo de desenvolvimento mental como uma espiral ascendente, antes do que linearmente. Terceiro, ela abre o caminho para estudar os elos entre os períodos individuais para o explanar da significância funcional de cada período prévio para o seguinte. Quarto, nossas hipóteses dividem o desenvolvimento em épocas e períodos em um modo que corresponde às leis internas desse desenvolvimento, não a meros fatores externos.

A significância prática da hipótese consiste no fato que ela serve como um auxílio para resolver a questão da suscetibilidade dos vários estágios do desenvolvimento da criança a tipos particulares de influência; ela oferece uma nova abordagem para o problema dos elos entre as várias instituições em nosso sistema educacional presente. De acordo com as exigências que seguem a partir dessa hipótese, no local em que temos uma ruptura em nosso atual sistema (instituições pré-escolares-escola) deveríamos ter um estreito elo orgânico. E, inversamente, no ponto em que agora temos continuidade (níveis primários-intermediários) deveria realmente haver uma alteração abrupta para um novo sistema educacional.

Naturalmente, somente investigações futuras mostrarão quão apuradamente nossas hipóteses refletem a realidade do desenvolvimento mental da criança. Contudo, consideramos justificada a publicação de nossas hipóteses, a despeito da sua escassez de material factual. Deveríamos relembrar as palavras de Friedrich Engels. "Se quiséssemos esperar até que o material para uma lei estivesse puro, então teríamos que suspender nossa pesquisa teórica até alcançar esse ponto e isso por si nos impediria de chegar à lei”. 


\section{NOTAS DE TRADUÇÃO'}

1. Há duas publicações do artigo de Elkonin. Ele foi publicado no Voprosy psikhologii Journal, em 1971, e depois republicado em 1989 no Izbrannie psihologicheskie trudi (Selected Psychological Works), edited by V. V. Davydov and V. P. Zinchenko (1989, p. 60-77). Embora não haja muitas diferenças entre as duas publicações, temos que considerar algumas circunstâncias concernentes às fontes que Elkonin usou. Assim, em 1971, ele tinha se referido ao texto de Vygotsky Problema Vozrasta como "manuscrito não publicado", enquanto que na edição de 1989 os editores mencionam (sem fazer qualquer referência ao número de páginas) que o trabalho de Vygotsky foi publicado no capítulo IV da obra Collected Works (VYGOTSKY, L. S., 1984).

2. Analisando a visão de Elkonin para o problema, o leitor deve levar em conta que em diferentes períodos ele modificou sua abordagem, sendo em certo sentido muito crítico de si mesmo. Temos alguma base para afirmar que ele mesmo não estava completamente satisfeito com a periodização baseada no princípio da atividade. Em particular, podemos encontrar alguns itens nos diários científicos de Elkonin, publicados na Rússia em 1989. Assim, em 1966 ele escreveu: "O ponto que a cognição ocorre somente imbricada à ação e por meio da ação é correto, mas ao mesmo tempo esse ponto é limitado [...] O que está no objeto é mais que o que está na ação, e mesmo várias ações com objetos não criam a representação completa do que esse objeto é [...]" (1989, p. 483). Por outro lado, "atividade dominante não necessariamente se torna a atividade dominante para toda criança [...]" (1989, p. 509).

3. "Concordemos em chamar aqueles tempos na vida da criança, que são distintos um dos outros por maiores ou menores crises, como ‘épocas'e 'estágios', respectivamente. Ainda, designemos como 'fases' aqueles tempos na vida de uma criança que diferem um do outro por mudanças graduais imperceptíveis".

4. Vygotsky usa o termo "períodos" e não idades, o que significa que há diferentes períodos numa mesma idade.

5. O termo "tipo de atividade dominante" não reflete o proeminente papel da atividade no desenvolvimento mental. O conceito russo original "veduschaya deyatelnost" está mais próximo do termo "atividade proeminente".

6. Em nota, Elkonin escreve: "Uma análise das condições históricas que cercam as origens desse dualismo e paralelismo está além do escopo do presente estudo. Devemos meramente remarcar que essas noções são o reflexo da alienação do homem dos produtos de sua atividade conforme essa alienação na verdade existe em uma sociedade de classes".

7. "A formação da criança como um membro da sociedade tem lugar durante a assimilação dos modos socialmente envolvidos de ações com objetos."

${ }^{7}$ Conforme Nikolai Veresov, 1971. 
8. O termo atividade de aprendizagem que Elkonin usa não tem nada em comum com a atividade formal de aprendizagem, desde que a atividade de aprendizagem, como desenvolvida nos trabalhos de Elkonin e V. Davydov não é formal por sua natureza e estrutura psicológica.

\section{REFERENCIAS}

BLONSKIY, P. P. Vozrastnaya pedologiya. Moscow, Leningrad: Rabotnik Prosveshcheniya, 1930

. Pedologiya. Moscow: Uchpedgiz, 1934.

EL'KONIN, D. B.; DRAGUNOVA, T. V. (Eds.). Vozrastnye i indvidual'nye osobemlosti mladshikh podrostltov. Moscow: Prosveshchenie, 1967.

FRADKINA, F. I. Psikhologiya igry v rannen detstve. Candidate's dissertation. Moscow, 1946.

LEONT'EV, A. N. Problemy razvitiya psikhi. 2. ed. Moscow: Mysl', 1965.

SLAVINA, L. S. Razvitie motivov igrovoy deyatel'nosti. Ivestiya APN RSFSR, n. 14, 1948.

VYGOTSKIY, L. S. Problema vozrasta. Unpublished manuscript.

WALLON, H. Mental development of the child. Paris: Armand Colin (Russian translation, Moscow: Prosveshchenie), 1967.

ZAPOROZHETS, A. V.; LISINA, M. I. (Eds.). Razvitiya obshcheniya so vzrsoslymi $i$ sversthikami u detey rannego i doshkol'nogo vozrasta, in press.

Texto recebido em 09 de junho de 2009.

Texto aprovado em 25 de janeiro de 2010. 